\title{
Academic Librarians and Research: A Study of Canadian Library Administrator Perspectives
}

\section{Selinda Adelle Berg, Heidi LM Jacobs, and Dayna Cornwall}

\begin{abstract}
Within the literature exploring the role of research in academic librarianship, very little attention has been paid to the perspectives of upper library administrators. This perspective is critical because library administrators play a key role in hiring, evaluating, supporting, promoting, and tenuring professional librarians. As a way of bringing the administrative perspective to these discussions, our study examines how library administrators within the Canadian Association of Research Libraries (CARL) view the role of research in their own libraries and within academic librarianship, as well as how they perceive the current and future climate for librarians' research. Our study reveals key areas in need of further research and identifies several issues that librarians and upper administrators would benefit from exploring together to advance discussions about research.
\end{abstract}

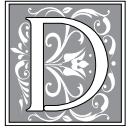

iscussions about professional librarians' anxiety and apprehension related to scholarly and research activities recur throughout the LIS literature. Should scholarly research be expected of academic librarians? How should such work be supported? What supports are needed to facilitate research activities? How does scholarly research mesh with the profession of librarianship? While much has been said about the perceptions of librarians on these issues, the expectations and viewpoints of university library administrators regarding the role of research in academic librarianship remains largely unexplored. It is critical that these perspectives be explored because library administrators play a key role in hiring, evaluating, supporting, mentoring, promoting, and tenuring professional librarians. Because library administrators are an integral part of the broad discussion about librarians and research, it is crucial that the administrative perspective be added to the existing conversations regarding academic librarianship and research. As a way of bringing the administrative perspective to these discussions, our study examines how library administrators within the Canadian Association of Research Libraries ${ }^{1}$ (CARL) view the role of research in their own libraries and within academic librarianship as well as how they perceive the current and future climate for librarians' research. ${ }^{2}$

Selinda Adelle Berg is Librarian and Heidi LM Jacobs is Information Literacy Librarian in Leddy Library at University of Windsor; e-mail: sberg@uwindsor.ca, hjacobs@uwindsor.ca; Dayna Cornwall is at Windsor Public Library, e-mail:dcornwall@windsorpubliclibrary.com. (C) 2013 Selinda Adelle Berg, Heidi LM Jacobs, and Dayna Cornwall, Attribution-NonCommercial (http://creativecommons.org/licenses/by-nc/3.0/) CC BY-NC 
In discussions of hiring, tenure, promotion, and workload, the primacy of librarians' research is becoming a more pressing issue in CARL libraries. Although the "Research Competencies for CARL Librarians" (2007) document states that academic librarians "are increasingly required to conduct research in order to meet institutional service needs and to further their own careers" ${ }^{3}$ and the "Core Competencies for 21st Century CARL Librarians" (2010) document lists "research and contributions to the profession" as one of the seven core competencies, many of the practical and professional realities of research activities in academic librarianship remain unresolved and contentious in discussions of promotion, tenure, job description and workload. ${ }^{4}$ For these vital discussions to progress and evolve, all perspectives need to be considered. Our study explores the undocumented perceptions of upper library administrators in CARL libraries so that these perspectives can be added to existing conversations related to research and scholarly activities in academic librarianship.

\section{Literature Review}

There is a general sense among library scholars that academic librarians ought to be engaged in research and publication for the health of the profession. Contemplating an overview of the research base in librarianship, Denise Koufogiannakis and Ellen Crumley conclude that establishing a more solid foundation in librarian research is a necessary component of healthy library culture and end with the assertion that "an environment in which research is considered part of what we do needs to be fostered and incorporated into our everyday practice as librarians." ${ }^{5}$ In recent years, many writers advocate specifically for the implementation of Evidence Based Library and Information Practice (EBLIP) at academic libraries: Allison Sivak argues that a strong culture of evidence-based practice will challenge librarians to define what we do based on how well our work meets the objectives of the profession. ${ }^{6}$

Despite a definite trend toward increased scholarly expectations and activity for academic librarians, the issue is still contentious: the debate rages as to whether librarians should in fact be pursuing publication when there are so many other professional responsibilities. Mary $\mathrm{K}$. Bolin sums up the argument against faculty status for librarians by noting that some librarians feel the demands of research and publication are unreasonable and onerous. She states that a contingent of authors and librarians feel librarians are ill-prepared to take on research due to a lack of education in research skills and the demands of an already heavy workload. ${ }^{7}$ Joseph Fennewald raises the related issue of whether librarians, in the end, participate in scholarship only because it is required by their institutions. ${ }^{8}$ Catherine Coker, Wyoma vanDuinkerken, and Stephen Bales, in contrast, advocate strongly for tenure status for academic librarians arguing that "library faculty members are on par with teaching faculty members in regard to scholarship and service" and, as such, "librarians require the protections offered by tenure to continue contributing to their profession," contributions that ought to be encouraged. ${ }^{9}$ However, as we have argued previously, "there is little to be gained by revisiting the long-standing debates about whether or not librarians should or should not do research" when research is currently and will continue to be an expectation for many academic librarians in Canada and elsewhere. ${ }^{10}$ Revisiting these debates without moving toward resolution keeps us at an impasse.

The debate in the literature over faculty status and research expectations for librarians is full of examples of obstacles that librarians face in the pursuit of scholarship. Ronald R. Powell, Lynda M. Baker, and Joseph J. Mika list the major barriers to scholarship that librarians confront: lack of time, inadequate education in research methods, lack of funding, and lack of institutional support. ${ }^{11}$ The 
recommendation seen most in literature on increasing librarian scholarship is that administration ought to provide more support for research. David Fox concludes that an increase in scholarly activity among academic librarians will not truly be successful without strong support from library administration. ${ }^{12}$ While Fox's survey offers vital information about the Canadian librarian perspective, what is missing from our current understanding of the research issue in Canadian academic libraries is the voice of the administration.

\section{Methodology}

During the winter semester of 2010, an online survey was distributed to 28 University Librarians (ULs) ${ }^{13}$ or equivalents of CARL member libraries: 24 English- or English/French- speaking universities and 4 exclusively French-speaking universities. Recruitment information as well as a link to the online questionnaire was sent via the CARL University Librarian listserv. The study design was approved by the University of Windsor's Research Ethics Board and the distribution of the survey was supported by the CARL Directors.

The questionnaire included 32 questions related to: demographic information; the expectations for and current level of research and scholarship for professional librarians at their institution; the barriers to and support provided for research by librarians at their institution; ULs' perceptions of librarians' engagement in research and scholarship and of research by professional librarians; the expectations for professional librarians to participate in research and scholarship; and demographic information about their home institution. The questionnaire used in the current study contained closeended survey questions and provided several opportunities for respondents to offer further information or clarification to their survey answers in an open-ended format. The survey took approximately 20 minutes to complete. The questionnaire was available in both French and English languages. For comparative purposes, several questions were modeled after David Fox's 2006 survey of librarians working at Canadian universities. To gather initial feedback on the survey questions and to pilot-test the survey technology, the survey was administered to three Associate ULs on two occasions in the fall of 2009. Based on feedback from the pilot testing, as well as feedback from an Educational Researcher at the University of Western Ontario, the survey was revised for final distribution to Canadian ULs in the winter semester of $2010 .{ }^{14}$

The response rate for the Englishspeaking universities was 79 percent: 19 of the 24 ULs solicited for response answered the online survey. Although a French-language survey was available, no ULs responded to the survey in French. ${ }^{15}$ Results were tabulated and analyzed using the IBM SPSS statistical software. Statistical analysis included both descriptive and inferential analysis.

\section{Results}

\section{Characteristics of Respondents}

To bring to light the perceptions and beliefs of the library administrators, confidentiality had to be ensured to encourage openness and honesty. In an effort to protect the identities of respondents in this relatively small sample, no identifying data (name, institution, province, region) was requested. General characteristics of the respondents are presented in table 1 .

Ten of the 19 respondents represented comprehensive universities, ${ }^{16}$ and nine of the respondents were from MedicalDoctoral universities. ${ }^{17}$ ULs' $^{\prime}$ mean years of experience in their current position was 12.5 years $(S D=8.5)$, with a range from 1 to 30 years. The respondents represented institutions with a wide-ranging size of librarian cohorts: the institutions represented by the respondents ranged in size from 20 to 130 librarians (mean = 45.8; $S D=28.33$ ).

Eighteen of the 19 responding ULs were from universities where librarians had fac- 
ulty or equivalent status. ${ }^{18}$ The prominence of faculty status within CARL libraries undoubtedly shapes the discussions related to research and scholarship within these libraries. Along with faculty status comes the formalized probationary period common in CARL libraries: ${ }^{19} 15$ of the 19 responding ULs reported a probationary period of greater than three years. Two ULs from institutions where librarians were not eligible for promotion through academic ranks reported a probationary period of only one year. Two other institutions did not make librarians eligible for promotion through academic ranks, each reporting a probationary period of three years.

\section{Expectations for and Level of Research at CARL Institutions}

The expectations for research by academic librarians varied across the responding institutions. Research is an expectation for every librarian at $9(48 \%)$ of the responding institutions, an expectation for some librarians at $6(31 \%)$ of the institutions, and not an expectation for any librarians at $4(21 \%)$ of the institutions. Of the 15 institutions requiring research, the expectations for research were most often outlined in collective agreements (87\% of respondents) and performance evaluation documentation (73.3\%). Job postings (48\%), job descriptions $(48 \%)$, and workload documents $(42 \%)$ were also popular sources for outlining the expectations for research. Two of the 15 ULs reported that, although expectations for research are not formally documented anywhere, there is an implicit expectation for research by all or some of the librarians at their institution. In spite of there being some level of expectation for participation in research for some or all librarians, of the 15 ULs who answered this question, only one UL's library provided formal benchmarks for annual review, promotion, and/or tenure. Furthermore, while the peer-reviewed journal article is often considered a benchmark for scholarship within many campus departments and faculties, no library had formal or informal expectations for publication in a peer-reviewed journal for promotion and tenure. It is clear from the ULs' responses that the expectation for research is inconsistent across CARL institutions and that few of those institutions provide formal documentation outlining the specifics of expectations for librarians.

\begin{tabular}{|l|c|c|l|c|c|}
\hline \multicolumn{7}{|c|}{ CABLE 1 } \\
\hline Characteristic & $n$ & $\%$ & Characteristic & $n$ & $\%$ \\
\hline Position & 19 & $100 \%$ & Primarily undergraduate & 0 & $0 \%$ \\
\hline University Librarian & 0 & $0 \%$ & Comprehensive & 10 & $53 \%$ \\
\hline Other & & & Doctoral & 9 & $47 \%$ \\
\hline \multicolumn{7}{|c|}{} & & Librarians eligible for promotion through \\
Librarians with faculty (or equivalent) \\
status
\end{tabular}




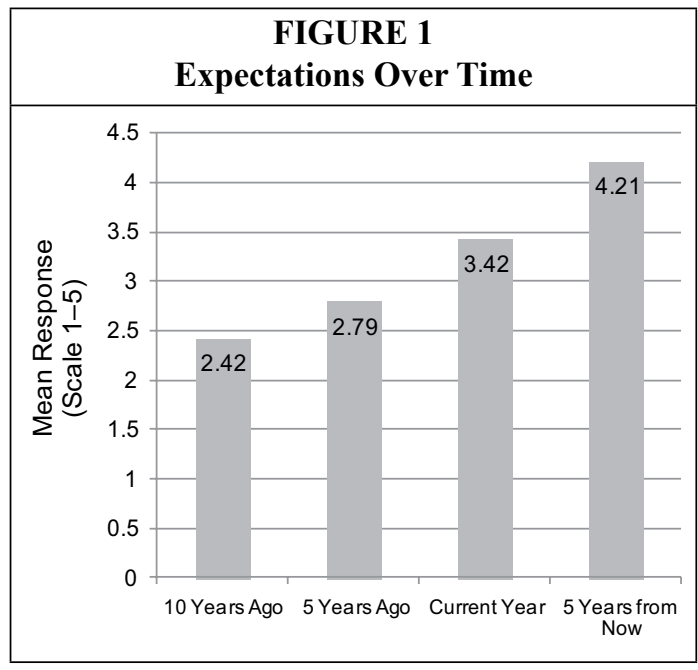

\section{Level of Research}

We asked ULs to indicate their perceptions of the level of research and scholarly activity of CARL institutions as a whole on a scale ranging from not at all active (1) to very active (5). The mean response was 2.44 . None of the 18 respondents indicated that CARL member libraries were active or very active, with 94 percent indicating that CARL librarians were moderately or slightly active. Respondents were subsequently asked to indicate the level of activity at their own institution in comparison. The majority of respondents (59\%)

\section{Expectations over Time}

ULs were asked to describe their perceptions of the importance of research on a scale ranging from not at all important (1) to very important (5) at four points in time: 10 years ago, 5 years ago, the current year, and 5 years from now (figure 1 ). In a one-way multiple regression analysis, no significant difference $(p>.05)$ was found between the mean level of expectations 10 years ago and the mean level of expectations 5 years ago. There was, however, significant difference $(p=.008)$ in the means between 5 years ago and the current year, as well as a significant difference $(p=.00)$ between the current year and 5 years from now. These results indicate that ULs observed a significant shift in research and scholarly expectations in the past 5 years and that they expect the trend to continue into the future. When respondents were offered the opportunity to describe in an open-ended way what they felt contributed to the change, ULs indicated that factors external to individual librarians precipitated the change. The most cited factors include: institutional expectations; faculty/collective agreements; new administrative emphasis; and a culture of evidence-based decision making. Only two respondents highlighted librarians' individual interests in research as a contributor to the change. indicated their institutions were equally active as the other CARL libraries. Six $(35 \%)$ indicated that their institutions were more active and one library $(6 \%)$ indicated that they were less active. Because ULs perceive CARL institutions to be relatively inactive in terms of research and scholarly activities, it is not surprising that 17 of the 18 ULs who answered this question perceived their institution to be as active as or more active than other CARL libraries. These findings may also indicate a lack of understanding of the current level of research occurring across Canadian academic libraries and a need for more communication between Canadian libraries and librarians regarding research activities.

\section{Perceptions of Level of Expectations}

Because we noted that the expectations placed on librarians to publish are much discussed within the scholarly literature, we asked ULs to indicate their perceptions of publication expectations for the librarians at their library on the following scale: too low (1), adequate (2), or too high (3) (figure 2). Eight of the 17 respondents perceived the current expectations for research at their libraries as too low, eight perceived the expectations to be adequate, and one indicated that they felt the expectations were too high. Addition- 
ally, library administrators were asked to indicate their observation of how the majority of librarians at their institution currently perceive the level of expectation for publication (figure 2). While ULs felt that current expectations for publication were either "too low" or "adequate," they noted they perceived their librarians felt these expectations were either "adequate" or "too high." A paired t-test revealed a significant difference $(p=.005)$ between the administrators' perceptions of the level of expectation for publication (mean $=1.33 ; \mathrm{SD}=.492$ ) and the administrators' observations of the librarians' perceptions of the level of expectation for publication (mean $=2.00, \mathrm{SD}=.426$ ). This finding raises questions about why ULs identify a gap between their own perceptions and those of their librarians. Further studies of this gap in perceptions are warranted.

\section{Barriers and Support for Research at Canadian Academic Libraries}

To explore additional elements of the research environment, we asked ULs about their perceptions of the barriers librarians face related to research as well as their observations of how librarians perceive the barriers to engaging in research. ULs indicated the degree to which a series of barriers affect librarians' ability to research: No effect (1) to High hindrance (4) (table 2). Further, ULs specified the degree to which they believe that librarians perceived the effect of the same barriers on librarians' ability to do research. A paired t-test was conducted to determine if ULs perceived the hindrance of these barriers differently than they felt their librarians perceived the hindrance. While results indicated that administrators believe that "lack of skill" and "lack of motivation" are key barriers to academic librarians' research, results also indicate that ULs believed that librarians perceive "lack of skills" and "lack of motivation" as significantly less of a hindrance than ULs perceive them $(p=.008$ and .029 respectively). Similarly, ULs felt librarians saw "lack of funds," "lack of time," and "lack of support" as greater barriers than ULs perceived them to be ( $p=.015, .001$, .011 respectively). Responses to the questions about research barriers indicate that ULs recognize a disconnection between their perceptions and their librarians' perceptions of barriers to research and scholarship. ULs perceived that librarians overestimate the barriers of lack of time, lack of funds, and lack of support and underestimate the barriers related to lack of skills and lack of motivation. Reading our findings alongside Fox's, the ULs in our study have accurately captured Ca-

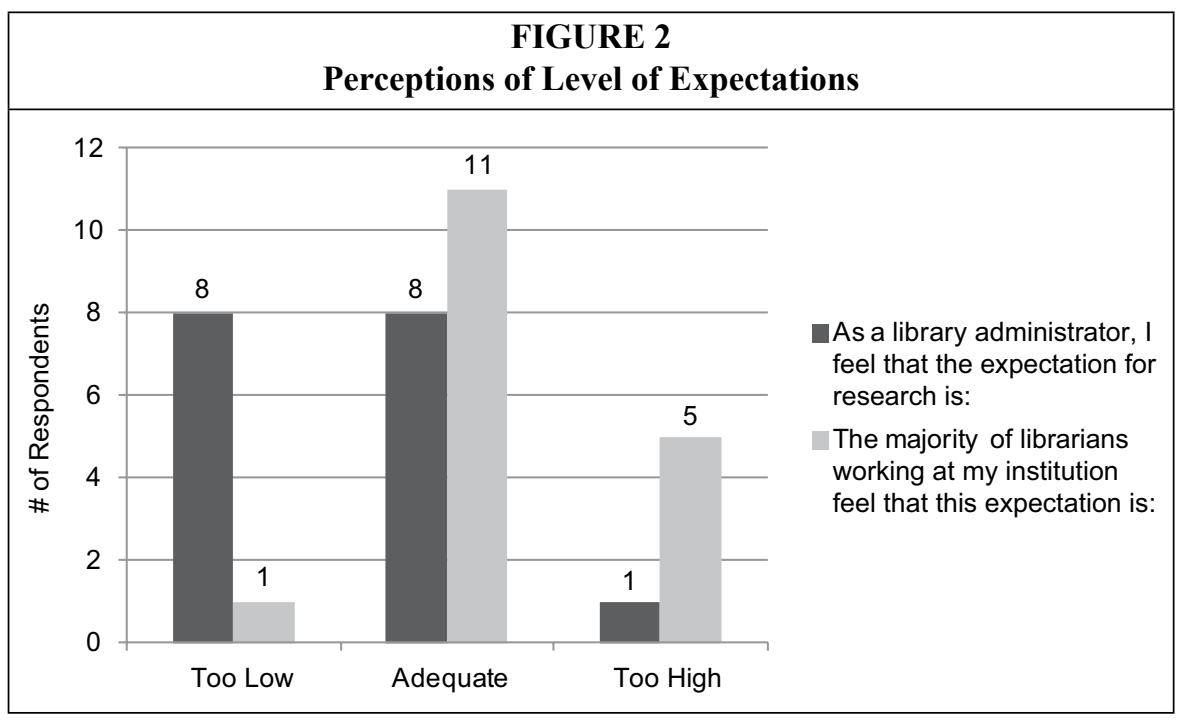




\begin{tabular}{|c|c|c|c|c|c|c|}
\hline \multicolumn{7}{|c|}{$\begin{array}{c}\text { TABLE } 2 \\
\text { Barriers to Research by Librarians }\end{array}$} \\
\hline Pair & & & Mean & $N$ & SD & Sig (p) \\
\hline \multirow[t]{2}{*}{1} & \multirow[t]{2}{*}{ Lack of time } & Admin. & 2.58 & 19 & .769 & $* .001$ \\
\hline & & Librarians & 3.47 & 19 & .905 & \\
\hline \multirow[t]{2}{*}{2} & \multirow[t]{2}{*}{ Lack of funds } & Admin. & 2.42 & 19 & .902 & $* .015$ \\
\hline & & Librarians & 2.79 & 19 & .918 & \\
\hline \multirow[t]{2}{*}{3} & \multirow[t]{2}{*}{ Lack of skills } & Admin. & 3.12 & 17 & .697 & $* .008$ \\
\hline & & Librarians & 2.59 & 17 & .618 & \\
\hline \multirow[t]{2}{*}{4} & \multirow[t]{2}{*}{ Lack of support } & Admin. & 2.00 & 18 & .686 & $* .001$ \\
\hline & & Librarians & 2.72 & 18 & .958 & \\
\hline \multirow[t]{2}{*}{5} & \multirow[t]{2}{*}{ Lack of writing skills } & Admin. & 2.00 & 18 & .767 & .096 \\
\hline & & Librarians & 1.72 & 18 & .752 & \\
\hline \multirow[t]{2}{*}{6} & \multirow[t]{2}{*}{ Lack of motivation } & Admin. & 2.50 & 18 & .985 & $* .029$ \\
\hline & & Librarians & 2.17 & 18 & .857 & \\
\hline \multirow[t]{2}{*}{7} & \multirow[t]{2}{*}{ Lack of questions } & Admin. & 1.89 & 18 & 1.132 & .430 \\
\hline & & Librarians & 2.00 & 18 & .907 & \\
\hline \multirow[t]{2}{*}{8} & \multirow[t]{2}{*}{ Lack of guidelines } & Admin. & 2.28 & 18 & 1.018 & .187 \\
\hline & & Librarians & 2.44 & 18 & 1.042 & \\
\hline \multirow[t]{2}{*}{9} & \multirow[t]{2}{*}{ Lack of experience } & Admin. & 3.11 & 18 & .676 & .816 \\
\hline & & Librarians & 3.06 & 18 & .802 & \\
\hline \multirow[t]{2}{*}{10} & \multirow[t]{2}{*}{ Lack of research culture } & Admin. & 2.79 & 19 & .918 & .578 \\
\hline & & Librarians & 2.68 & 19 & .946 & \\
\hline
\end{tabular}

nadian academic librarians' perceptions regarding research barriers. ${ }^{20}$ However, our study reveals that ULs saw additional barriers. Given ULs' perceptions that research expectations have changed and will continue to change, another survey of Canadian librarians could update Fox's 2006 findings.

\section{Time for Research and Scholarship}

Time is perhaps the most cited issue noted in the professional literature in relation to librarians and scholarship. ${ }^{21}$ Virtually every published article about librarians and research notes that time constraints of librarians are major obstacles. To better understand the current efforts being placed on research endeavors, ULs were asked about the recommended, actual, and ideal time spent on research. Twelve of 16 respondents indicated that there was no recommended percentage of time for librarians to spend on research within their workload. Only four respondents indicated that there was a recommended percentage for time allocated for research $(10 \%, 15 \%, 20 \%, 25 \%)$. Most often, recommended percentages were articulated in the collective agreements of the librarians' unions or faculty associations. Although only four institutions provided a recommended percentage of workload time to be dedicated to research, ULs reported that librarians at their institutions spend between 0 and 20 percent of their time doing scholarly activities. A paired t-test indicated a significant difference $(p=.001)$ in the percentage of time librarians cur- 
rently spend doing research ( mean $=11.5$; $\mathrm{SD}=6.5)$ and the ULs reported "ideal" percentage of time (range $5 \%-30 \%$; mean $=18.75 ; \mathrm{SD}=7.2$ ) for research by librarians. ULs desired significantly more time to be devoted to research: a desire of up to a 25 percent increase in time committed to research and scholarly activities was reported. These results align well with the actual and ideal percentages of time for research specified by librarians in Fox's 2007 survey where librarians reported that approximately 10 percent of their time is committed to research and scholarship, while 15 percent was identified as the ideal percentage of time. ${ }^{22}$

We attempted through statistical analysis to identify patterns between the time spent on research and other institutional characteristics; however, few meaningful or significant patterns emerged. Some correlation may exist between a longer time to achieve tenure and a higher percentage of time (significant at $10 \%$ ). Few other patterns were shown at any level of significance. It was anticipated that some patterns may emerge between size of institution, research focus, confidence in ability to support, and importance of research in a UL's career; however, these patterns did not emerge in the current data. Subsequent studies in this area might reveal more relationships.

\section{Supports}

ULs were asked to identify what supports are made available to librarians taking part in research and scholarship at their institutions (table 3). The most common supports reported were research leaves $(84.2 \%)$ and sabbaticals (84.2\%). These two most common supports are also those most often dictated by collective agreements and employment contracts. Supports that are more voluntary and less formalized such as peer support groups, mentoring programs, and research assistance were less commonly available. Further, ULs were asked to describe how confident they were in their institution's ability to support librarians in their research and scholarly endeavors on a scale ranging from not at all confident (1) to very confident (5). Approximately two thirds, 12 of 19 respondents, indicated they were either confident or very confident in their institution's abilities to support librarians' research. Six respondents reported that they were somewhat confident, and one respondent indicated only slight confidence. The mean was $3.84(\mathrm{SD}=.898)$. Overwhelmingly, our ULs felt confident in their institution's abilities to support librarian research. Other research indicates that institutional supports such as research and study leaves are not often taken advantage of by librarians. ${ }^{23}$ Supports, however, are only useful when they are taken advantage of and used. Further studies could explore why librarians have tended not to take advantage of these leaves. Although these institutional supports are available, are there administrative, institutional, or cultural factors discouraging librarians from taking advantage of these leaves? Or are librarians not taking advantage of these leaves for personal reasons?

\section{Perceptions of Librarian Engagement in Research}

To better understand ULs' perceptions of librarians' engagement in research, we asked several questions that related to their perceptions of their librarians' at-

\begin{tabular}{|c|l|c|c|}
\hline \multicolumn{5}{|c|}{ TABLE 3 } \\
\hline Support Available to Librarians \\
\hline Rank & \multicolumn{1}{|c|}{ Support } & $\boldsymbol{n}$ & Percentage \\
\hline 1 & Research leaves & 16 & 84.2 \\
\hline 2 & Sabbaticals & 16 & 84.2 \\
\hline 3 & Office support & 11 & 57.9 \\
\hline 4 & Research skills training & 11 & 57.9 \\
\hline 5 & Release time & 9 & 47.3 \\
\hline 6 & Peer support groups & 7 & 36.8 \\
\hline 7 & Mentoring programs & 5 & 26.3 \\
\hline 8 & Research assistants & 4 & 21.1 \\
\hline
\end{tabular}




\begin{tabular}{|c|l|c|c|c|}
\hline \multicolumn{7}{|c|}{ TABLE 4 } \\
\hline Characteristics of Librarian Engagement in Research \\
\hline 1 & \multicolumn{1}{|c|}{ Librarians' belief in the contributions of research } & 18 & 3.72 & 1.127 \\
\hline 2 & Librarians' willingness to engage in research & 18 & 3.44 & 1.042 \\
\hline 3 & Librarian'' enthusiasm to engage in research & 17 & 3.41 & 1.064 \\
\hline 4 & Librarians' confidence in ability to do research & 18 & 3.28 & 0.669 \\
\hline 5 & Librarian' commitment to a sustained research program & 18 & 2.78 & 1.114 \\
\hline 6 & Librarians' anxiety about engaging in research & 18 & 2.78 & .878 \\
\hline 7 & Librarians' level of research skills & 18 & 2.67 & 0.686 \\
\hline
\end{tabular}

titudes toward participating in research activities and their overall ideas about research and librarianship. ULs rated their librarians' engagement and involvement in research and scholarship on a scale from very low (1) to very high (4) (table 4). Results indicate that while ULs perceive their librarians to have a relatively high level of willingness and enthusiasm to engage in research and scholarship, ULs also believe that librarians at their institutions have relatively low levels of research skills and low levels of commitment to a sustained research program.

To explore ULs' perceptions of what motivates librarians to participate in research and scholarship, ULs were asked to indicate the degree to which specific factors motivate their librarians on a scale ranging from not at all motivating (1) to very motivating (5) (table 5). The motivating factors included in our survey were modeled after David Fox's 2007 article, which asked a similar question of $\mathrm{Ca}$ nadian librarians. ${ }^{24}$ Our study, however, included the additional motivating factor of Promotion and Tenure, which was not included in Fox's original article. ULs perceived promotion and/or tenure to be the strongest motivating factor for research activity by librarians, followed by professional advancement and personal growth. Increased income and increased job security were ranked lowest in both our study and Fox's as motivators of research. Because job security and income are closely tied to promotion and tenure, their low ranking seems contradictory to the fact that the highest-ranked motivator was promotion and tenure. The top motivators identified by the responding ULs in this study are not consistent with Fox's 2006 survey of librarians, which found acquisition of knowledge and personal growth to be the highest. The inconsistencies of librarian perceptions reported by David Fox and the perceptions of ULs reported in our study reveal a gap between librarian and administrative perspectives that warrants further study.

\section{Impact}

Our study also sought to identify how ULs perceived the outcomes of librarians participating in scholarly research and the benefits to the librarians, library, and profession for research activities. ULs identified the greatest impact of librarians doing research as a stronger profession of librarianship, followed by more innovative thinking and better professional librarians and archivists. Abstract, intangible, nonquantifiable outcomes such as a stronger profession, more innovative thinking, and better professionals were ranked higher than more concrete, tangible, and quantifiable outcomes, such as better library services, stronger interfaculty relationships, and greater visibility on campus. The ULs in our study echo what Koufogiannakis and Crumley argue: research "can be thought of in terms of professional development and in giving back to one's profession. By conducting 


\begin{tabular}{|c|l|c|c|}
\hline \multicolumn{5}{|c|}{ MABLE 5 } \\
Motivations for Research and Scholarship \\
\hline Rank & \multicolumn{1}{|c|}{ Motivation } & Mean & SD \\
\hline 1 & Promotion and/or tenure & 4.167 & 1.167 \\
\hline 2 & Professional advancement & 3.944 & 1.079 \\
\hline 3 & Personal growth & 3.644 & 1.129 \\
\hline 4 & Improvement of library services & 3.611 & 0.891 \\
\hline 5 & Acquisition of knowledge & 3.444 & 0.956 \\
\hline 6 & Increased status/ prestige & 3.389 & 1.167 \\
\hline 7 & Development of innovative techniques & 3.278 & 1.096 \\
\hline 8 & Increased job security & 2.889 & 1.167 \\
\hline 9 & Increased income & 2.722 & 1.145 \\
\hline
\end{tabular}

research, [librarians] are adding to [the] field, which in turn will help improve many of our services and resources." 25 This finding raises questions to be explored further within discussions related to the value of the research enterprise for academic librarians. Perhaps the "value" of librarians' research is difficult to prove because the reasons it is most valued are abstract, intangible, and nonquantifiable.

\section{Discussion}

\section{Limitations of Study}

The pool of participants was limited to ULs at CARL-member institutions. CARL institutions were selected because of the consistency between institutions in terms of scope, structure, and organization of libraries. Even though the response rate was very high, the small population limited the level of statistical analysis possible. ${ }^{26}$

The survey was chosen as the method of data collection for the current study because it provided a safe methodology to ensure the confidentiality of library administrators to share their beliefs and perceptions of their environments. Additionally, the online questionnaire provided an efficient and inexpensive way to capture data from across the vast geography of Canada. Although the questionnaire was chosen for these reasons, the methodology did reveal some limitations. The survey method provides little opportunity for respondents to provide nuanced descrip- tions of the realities of their institutions or to indicate anomalies within their institutions. ULs were asked to provide the answer that best represents the realities of their institution; however, it was evident that some respondents struggled to find one answer to some of the survey questions. Academic libraries are, of course, complex, ever-changing environments with a diverse spectrum of librarians with varied backgrounds at different points in their careers. Some of the respondents indicated that there was not a consistent expectation across the cohort of librarians belonging to one institution. One respondent wrote in an open-ended question, "I have no single 'perception regarding the librarian/archivist" "and felt that the questionnaire encouraged administrators "to state a single perception of their entire cohort." The limitations can be attributed to the confines of questionnaire-designed research as we acknowledge above. Further research in this area, especially more qualitative research, would help to bring these vital nuances to the fore.

One respondent was also concerned that asking administrators to describe their own perceptions as well as their perceptions of how librarians think was an attempt to magnify "the differences of opinion that may exist between administrators and librarians." The intention of our survey was not to magnify differences of perception between librarians and ad- 
ministrators but instead to highlight the places where conversations between administrators and librarians need to occur.

\section{Connections through Disconnections}

Within our own results and the results of previous studies, it is easy to identify connections in librarians' and administrators' perceptions as well as disconnections. Disconnections should not necessarily be seen as an unwinnable "us against them" scenario; instead, these disconnections are opportunities to explore differences of opinion and move discussions about academic librarians' research into new terrain. Fox's study reveals an interesting disconnection related to research time: Canadian librarians in his study cited lack of time as a major inhibitor for research, yet very few reported taking advantage of the research leaves and sabbaticals to which they are entitled. Similarly, in our study, there was a disconnection between ULs' perceptions of research and publication expectations being too low and their perception of librarians' believing these expectations to be too high. Another disconnection existed between ULs' views of the barriers to research and how they perceive their librarians' views on the barriers to research. These disconnections reveal scenarios worth further investigation and discussion. We believe the disconnections revealed in our study are generative sites of inquiry and sites where we can take existing discussions in new directions. How do these disconnections manifest themselves in the work lives of academic librarians and the work of academic libraries? How might we turn disconnections into new points of connection? If we are going to move discussions about academic librarianship and research into more productive terrain, we need to explore these disconnections since they reveal the complexity of the research situation in CARL libraries and suggest issues that need resolution before we can progress. While our study has focused on CARL libraries, these issues are not specific to CARL: undoubtedly, these issues surface in academic libraries across North America.

It is clear from our research that there is no single model for librarians' research across the CARL institutions or even within a single institution. That there is not a single model for librarians' research across Canada may not be surprising. When embarking on this project, we had anticipated we would find relationships between certain characteristics of the institution (size, administrator experience) and the expectations for research (time devoted to research, support provided). Numerous inferential statistical analyses were run, but few significant relationships emerged. This may in part be due to the wide variance of models of research currently working within Canadian academic libraries. Nevertheless, research expectations are a common issue that should be discussed on a national level.

Another significant finding from our study is that across responding CARL libraries, only one UL reported having formal research expectations at their institution and none of the libraries reported having explicit, formal, or written expectations regarding expectations or requirements for publication. Further, no UL reported the articulation of publication benchmarks for promotion and tenure. The absence of clear expectations regarding research across CARL institutions presents challenges for both ULs and librarians across CARL institutions, especially those who use research as a factor in promotion and tenure decisions either formally or informally. Our study also confirms Fox's 2007 finding that the "requirement for formal scholarship by Canadian research librarians appears to be a growing trend, and, yet, there are no commonly accepted norms for the appropriate balance between scholarship and other professional responsibilities. ${ }^{\prime 27}$ Articulating formal requirements regarding research is clearly one area that needs work across Canada so that expectations for workload, promotion, and tenure are more transparent to all parties. 
CARL ULs consistently reported a commitment to supporting research activities in academic librarianship and expressed confidence in their librarians' abilities to participate in research activities. Such a finding suggests that CARL ULs view research by librarians as not only something desirable within their institutions but also something that is possible. Significantly, CARL ULs' responses suggest a willingness to work with librarians to help facilitate their research activities. Our findings suggest that, even though there are disconnections between administrators and librarians, this is not an "us vs. them" situation. It is evident that a climate exists where both librarians and library administrators can come together to work through the factors needed for the development of strong research cultures in their individual libraries and across Canada.

\section{Conclusion}

As researchers, we are cognizant of the limitations of the survey/questionnaire format for research studies of this nature. In devising this survey, we understood that we would be unable to capture the overall research environment of academic libraries in Canada in a single research tool or a single research study. Additionally, we did not imagine that our study would be anything but a single step in a larger exploration looking at research culture in Canadian libraries. In spite of these limitations, our survey does raise some significant areas of inquiry that merit further investigation and study. In particular, we see the need for ULs and librarians in individual libraries and across Canada to have the conversations necessary so that realistic and meaningful documentation regarding research expectations can be outlined for the purposes of promotion, tenure, and workload. Concurrently, concrete recommendations and programs should be established so that these research expectations can be met within librarians' workloads. Finally, more conversations need to happen surrounding the role of research within librarianship and within the careers of academic librarians. It is critical that these issues are brought to the fore so that we may continue to investigate the climate for academic librarians and research activities not just in Canada but internationally.

\section{Notes}

1. The Canadian Association of Research Libraries (CARL) consists of 29 university libraries plus the Library and Archives Canada, Canada Institute for Scientific and Technical Information (CISTI), and the Library of Parliament. Membership is institutional and is open primarily to libraries of Canadian universities that have doctoral graduates in both the arts and the sciences. Four CARL institutions were not included in the study: three institutions are national nonacademic institutions and one joined CARL after the study's start date. "About CARL" (2011), available online at http://carl-abrc.ca/en/about-carl.html [accessed 4 January 2011].

2. Our survey asks specifically about librarians and archivists. In this article, we use the term "librarian" to include all members of a library's professional complement. In this context, librarians then should be interpreted as both librarians and archivists.

3. "Research Competencies for CARL Librarians"(2007), available online at http://carl-abrc. ca/uploads/pdfs/carl_lewg_product_brief-en.pdf [accessed 9 January 2012].

4. "Core Competencies for 21st Century CARL Librarians" (2010), available online at http:// carl-abrc.ca/uploads/pdfs/core_comp_profile-e.pdf [accessed 9 January 2012].

5. Denise Koufogiannakis and Ellen Crumley, "Research in Librarianship: Issues to Consider," Library Hi Tech 24, no. 3 (2006): 338.

6. Allison Sivak, "Activating Research in the Library Community," Feliciter 53, no. 1 (2007): 8-11.

7. Mary K. Bolin, "A Typology of Librarian Status at Land Grant Universities," Journal of Academic Librarianship 34, no. 3 (2008): 220-30.

8. Joseph Fennewald, "Research Productivity among Librarians: Factors Leading to Publications at Penn State," College E Research Libraries 69, no. 2 (2008): 104-16.

9. Catherine Coker, Wyoma vanDuinkerken, and Stephen Bales, "Seeking Full Citizenship: A Defense of Tenure," College \& Research Libraries 71, no. 5 (2010): 417. 
10. Heidi LM Jacobs, Selinda Berg, and Dayna Cornwall, "Something to Talk About: Rethinking Conversations on Research Culture in Canadian Academic Libraries," Partnerships 5, no. 2 (2010): 7.

11. Ronald R. Powell, Lynda M. Baker, and Joseph J. Mika, "Library and Information Science Practitioners and Research," Library and Information Science Research 21, no. 1 (2002): 49-72.

12. David Fox, "Finding Time for Scholarship: A Survey of Canadian Research University Librarians," portal: Libraries and the Academy 7, no. 4 (2007): 451-62.

13. In Canadian universities, University Librarians hold positions equivalent to Deans.

14. For their assistance and insight, we thank: Ken Meadows, Educational Researcher, University of Western Ontario; Dan Edelstein, Academic Data Specialist, University of Windsor; and Kristi Thompson, Data Librarian, University of Windsor.

15. The lack of response to the French survey may be because, as Fox has described, Frenchspeaking universities in Canada currently "do not experience the same level of academic benefits and obligations as research university librarians elsewhere in Canada" (8). "The Scholarship of Canadian Research University Librarians," Partnership: the Canadian Journal of Library and Information Practice and Research 2, no. 2 (2007), available online at http://journal.lib.uoguelph.ca/index. php/perj/article/view/305/531 [accessed 9 January 2012].

16. Comprehensive universities have a significant amount of research activity and a wide range of graduate and undergraduate programs, including professional degrees.

17. Medical Doctoral universities offer a broad range of Ph.D. programs and research; all institutions in this category have medical schools.

18. As Fox describes, "a variety of circumstances exist in the CARL libraries with respect to academic status. Conditions range from full faculty status (with an obligation to research and publish, eligibility for sabbatical leave, and criteria for tenure and promotion similar to those of university professors) to the status of support staff in a separate bargaining unit. The most common situation seems to be membership in the faculty association for the purpose of contract negotiation, but with a status, pay scale, and expectations for scholarship lower than for the teaching faculty" (545). "A Demographic and Career Profile of Canadian Research University Librarians," Journal of Academic Librarianship 33, no. 5 (2007): 540-50.

19. The probationary period, here, refers to the time period prior to librarians obtaining permanent or tenured status. The Canadian Association of University Teachers (CAUT) states that "[ $\mathrm{t}$ ]he period of the tenure-track appointment should be adequate for the Member to establish a record that can speak to the stated conditions and criteria." "Policy Statement on Renewal of Tenure-track Appointments," available online at www.caut.ca/pages.asp?lang=1\&page $=292$ [accessed 27 May 2012].

20. Fox, "Finding Time," 460.

21. In The Nature of Research: Inquiry in Academic Contexts (London: Routledge, 2001), Angela Brew describes how juggling expectations and demands in academic settings is par for the course: "Individual academics have to do a balancing act" (47). She describes how "In the day-to-day work of each academic, each department and each faculty, and in the management decisions of universities, research and teaching occupy contested space... How often does spending time on research feel like time taken out of academic duties? If in no other arena, research and teaching compete for time in the life of the busy academic. Teaching takes time away from research. Research is time taken out of teaching. Every individual academic who has both responsibilities has to negotiate this contested space on a daily basis" (46). Further, Fox ("Finding Time") reminds us that librarians' struggles to balance research along with other professional activities and requirements are not unique to us: "The 'struggle to juggle' seems to be a universal aspect of academic life" (461).

22. Fox, "Finding Time," 457. The Canadian Association of University Teachers' "Model Clause on the Scholarly Activities of Academic Librarians" (2003) states that "The pursuit of research, study, educational and other scholarly activities shall constitute a normal component of a librarian's workload" and that "A librarian shall have the right to devote up to $40 \%$ of normal workload to the pursuit of research, study, educational and other scholarly activities." "Model Clause on the Scholarly Activities of Academic Librarians," Canadian Association of University Teachers (CAUT), available online at www.caut.ca/pages.asp?lang=1\&page $=412$ [accessed 9 January 2012].

23. Fox's 2007 study ("Finding Time") reveals that while 73 percent of the Canadian librarians he surveyed were eligible for study leave and 31 percent were able to take some form of short-term research leave, "less than a quarter of the librarians surveyed had participated in any particular type of leave" and only 21 percent of the overall sample had taken advantage of the opportunity for sabbatical leave" (459).

24. Ibid.

25. Koufogiannakis and Crumley, "Research in Librarianship," 337.

26. There was a subsequent attempt to extend the survey to Associate University Librarian; however, the response rate from the Associate University Librarians was so limited the data was unusable and could not be included in the study.

27. Fox, "Finding Time," 452. 


\section{Host ACRL Standards, Scholarly Communication Workshops in 2014}

Today's academic and research librarians increasingly act as change agents in the higher education community while being called on to demonstrate their value on campus. ACRL 's one-day scholarly communication and Standards for Libraries in Higher Education workshops help you achieve those goals through learning more about these important topics at your campus, chapter, or consortia. Facilitated by our team of expert presenters, both workshops provide a framework for libraries to grow, innovate, lead, and succeed.

\section{Scholarly Communication: From Understanding to Engagement}

To help empower our community in accelerating the transformation of the scholarly communication system, ACRL is pleased to offer the day-long workshop, "Scholarly Communication: From Understanding to Engagement." The workshop helps participants in very practical ways, such as preparing for library staff or faculty outreach, contextualizing collection development decisions to internal and external stakeholders, and initiating or supporting new models for scholarly communication. Details are available on the ACRL website at www.ala. org/acrl/issues/scholcomm/roadshow.

"The workshop helped me connect complex issues like the relationship between the open movement, copyright, and economics in a coherent way. It is good to have this conceptual framework moving forward." - Scholarly Communication Workshop Participant

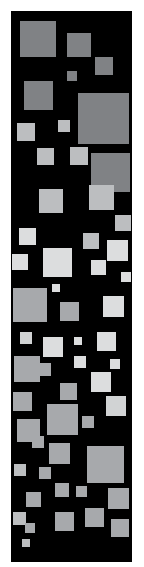

\section{Standards for Libraries in Higher Education Training Workshops}

The ACRL Standards for Libraries in Higher Education provide a framework for planning and assessment that can be adapted for a variety of circumstances including strategic planning, program review, and accreditation self-study. ACRL's "Planning, Assessing, and Communicating Library Impact: Putting the Standards for Libraries in Higher Education into Action" workshop provides information on using the standards and other foundational documents as a framework to develop benchmarks, evaluate quality and performance, and demonstrate value. Details are available on the ACRL website at www.ala.org/acrl/standardsworkshop.

"In this workshop, the assessment process was presented in a clear, understandable way. Great job on difficult material!" - Standards Workshop Participant

Hosts are responsible for the full cost of both workshops and may choose to recover costs through registration fees.

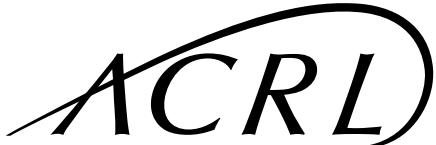

Advancing learning Transforming scholarship

Association of College \& Research Libraries

A division of the American Library Association

50 E. Huron, Chicago IL 60611 | 1.800.545.2433 | acrl @ala.org 